\title{
The paleoclimate record in the ice core at Dome Fuji station, East Antarctica
}

\author{
Okitsugu Watanabe, ${ }^{1}$ Kokighi Kamiyama, ${ }^{1}$ Hideaki Motoyama, ${ }^{1}$ Yoshiyuki Fujii, ${ }^{1}$ \\ Hitoshi Shoji, ${ }^{2}$ Kazuhide Satow ${ }^{3}$ \\ ${ }^{1}$ National Institute of Polar Research, Itabashi-ku, Tokyo 173-8515, Japan \\ ${ }^{2}$ Kitami Institute of Technology, Koen-cho 165, Kitami, Hokkaido 090-8507, Japan \\ ${ }^{3}$ National Nagaoka College of Technology, Nishikatagai-cho 888, Nagaoka, Niigata 940-0817, Japan
}

\begin{abstract}
The Antarctic ice sheet preserves paleoclimate information in the form of physical and chemical stratigraphy. A deep ice core down to $2503 \mathrm{~m}$ depth was drilled at Dome Fuji station, East Antarctica, during the 1993-96 Japanese Antarctic Research Expedition inland operations. Oxygen isotope measurements were conducted on $50 \mathrm{~cm}$ long samples selected from the entire core length. A paleo-temperature profile was obtained for the past $340 \mathrm{ka}$ by assuming the same conversion factors for the past relation as exist today between isotope ratio and both surface temperature and accumulation rate, in the inland region of Dronning Maud Land. The environmental-index profiles such as major chemical and dust contents coincide quite well with Vostok ice-core data in general but not in detail. Detailed analysis of these climatic and environmental signals is in progress.
\end{abstract}

\section{INTRODUCTION}

The Japanese Antarctic Research Expedition (JARE) has planned and executed the Dome Fuji Program, a comprehensive glaciological research project focusing on deep ice coring and analysis for retrieving past environmental information

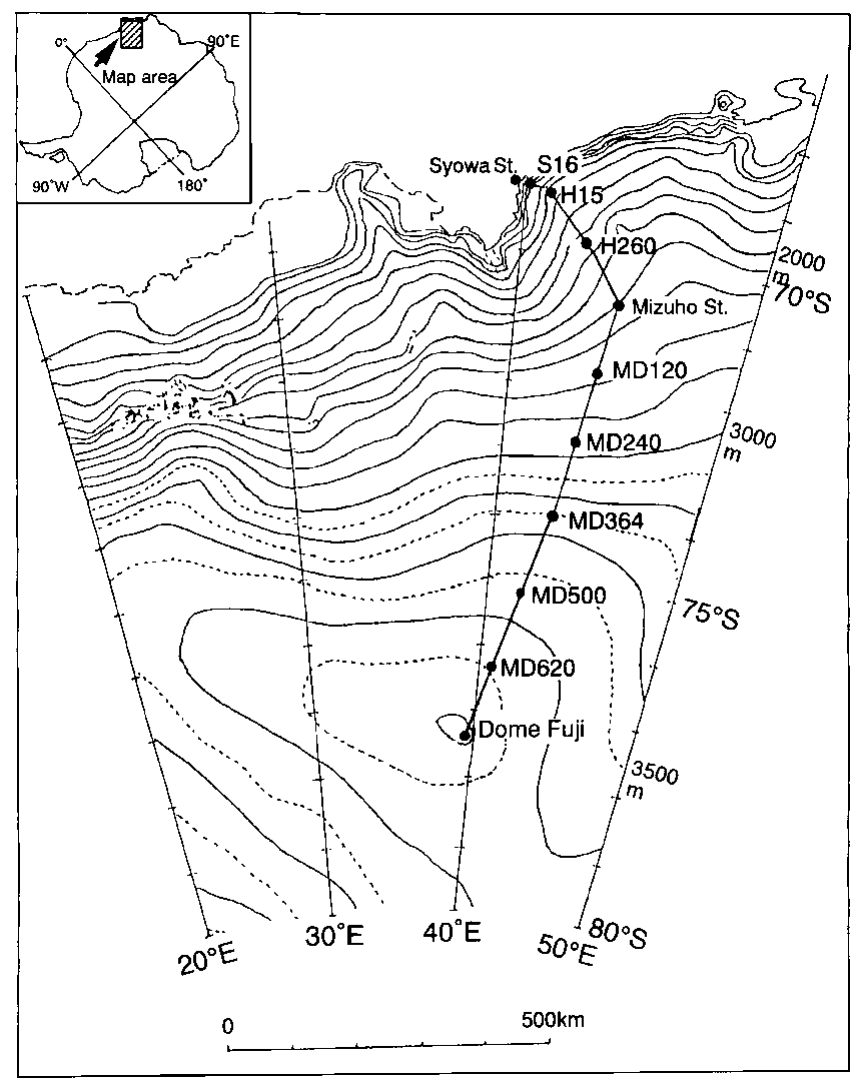

Fig. 1. Location of Dome Fuji station and traverse routes between Syowa, Mizuho and Dome Fuji stations. recorded in the Antarctic ice sheet. A continuous deep ice core down to $2503 \mathrm{~m}$ depth was recovered at Dome Fuji station, east Dronning Maud Land, Antarctica $\left(77^{\circ} 19^{\prime} 01^{\prime \prime} \mathrm{S}\right.$, $39^{\circ} 42^{\prime} 12^{\prime \prime} \mathrm{E}$; $3810 \mathrm{~m}$ a.s.l.; ice thickness, $3028 \mathrm{~m}$; $10 \mathrm{~m}$ snow temperature $-58^{\circ} \mathrm{C}$ ) by using a JARE mechanical drill in a liquid-filled hole during the 1993-97 inland operations (Fig. 1). The core quality is excellent even in the brittle zone, 500$860 \mathrm{~m}$ deep, where the ice was fragile during the in situ corecutting procedure (Dome-F Deep Coring Group, 1998; Dome-F Ice Core Research Group, 1998).

\section{STABLE-ISOTOPE MEASUREMENTS}

Oxygen-isotope measurements were made on $50 \mathrm{~cm}$ long samples selected from the entire core length. The present paper shows the results obtained from samples at $2.5 \mathrm{~m}$ depth intervals. The ${ }^{18} \mathrm{O} /{ }^{16} \mathrm{O}$ ratio obtained from each sample is converted to $\delta^{18} \mathrm{O}$, the relative deviation from that in Standard Mean Ocean Water (Fig. 2).

Glaciological data for east Dronning Maud Land (EDML) have been produced by JARE field activities. A systematic glaciological survey has revealed characteristic features of accumulation rate, $10 \mathrm{~m}$ depth snow temperature and $\delta^{18} \mathrm{O}$ distribution of the snow deposit, related to elevation. $\delta^{18} \mathrm{O}$ is a function of the condensation temperature of vapor in the atmosphere, and the average $\delta^{18} \mathrm{O}$ of the snow pit or surface snow core can be expressed in terms of the annual mean air temperature which is approximately equal to the $10 \mathrm{~m}$ depth snow temperature. An empirical equation was obtained for a relationship between accumulation rate, $\beta\left(\mathrm{cm}\right.$ ice $\left.\mathrm{a}^{-1}\right)$, and $\delta^{18} \mathrm{O}(\%)$ in the area above $2200 \mathrm{~m}$ a.s.l. as follows:

$$
\beta=3.11 \exp \left[0.0713\left(\delta^{18} \mathrm{O}+54.1\right)\right] .
$$

This empirical equation gives an accumulation rate of 

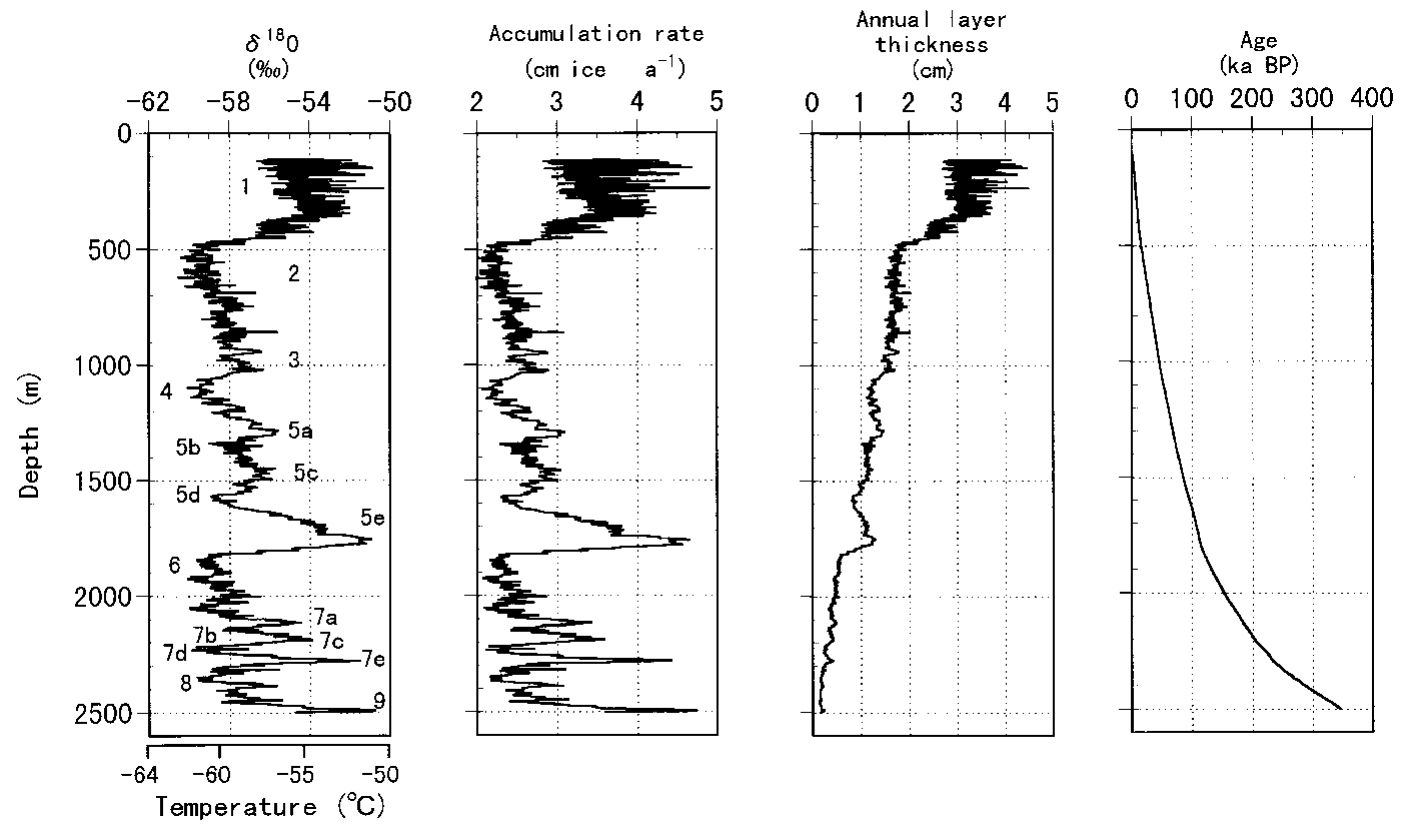

Fig. 2. $\delta^{18} \mathrm{O}$ and estimated accumulation-rate profiles, annual layer thickness profiles and an age-depth curve for the Dome Fuji deep ice core (preliminary results as of July 1998). 1-9, marine isotope stages.

$3.11 \mathrm{~cm}$ ice $\mathrm{a}^{-1}$ at Dome Fuji $\left(\delta^{18} \mathrm{O}=-54.1 \%\right.$, which is within the range of $2.8-3.3 \mathrm{~cm}^{-1} \mathrm{a}^{-1}$ obtained by a study on a shallow core from Dome Fuji (Watanabe and others, 1997).

Another empirical relation obtained from the EDML glaciological survey was used to convert $\delta^{18} \mathrm{O}(\% \mathrm{o})$ to mean annual temperature (snow temperature at $10 \mathrm{~m}$ depth), $\mathrm{T}_{10}$ $\left({ }^{\circ} \mathrm{G}\right)$ as follows:

$$
\delta^{18} \mathrm{O}=0.852 T_{10}-7.92 .
$$

The $\beta$ value calculated is also shown in Figure 2, where we assume that the spatial relationship (Equation (1)) is valid in the depth domain. This profile clearly shows three glacialinterglacial cycles.

\section{GHEMICAL GONSTITUENTS}

Chemical samples $7-10 \mathrm{~cm}$ long were cut from the core at in- tervals depending upon the depth. The surface $5 \mathrm{~mm}$ of chemical samples were scribed using a ceramic knife in a clean bench in a home cold laboratory. The firn sample was then stored in a Teflon sealed bottle and melted just before the measurement, as reported by Watanabe and others (1997). The ice sample was stored in a plastic bag and rinsed with ultra-pure water just before the melting and measurements.

The chemical constituents of the core samples were measured by ion chromatography (isocratic system for cations and gradient system for anions with Dionex DX-500, as reported by Watanabe and others (1997)). Ions measured were $\mathrm{Na}^{+}$, $\mathrm{NH}_{4}{ }^{+}, \mathrm{K}^{+}, \mathrm{Mg}^{2+}, \mathrm{Ca}^{2+}, \mathrm{F}, \mathrm{Cl}^{-}, \mathrm{SO}_{4}{ }^{2-}, \mathrm{NO}_{2}{ }^{-}, \mathrm{NO}_{3}{ }^{-}$, $\mathrm{HCOO}^{-}, \mathrm{CH}_{3} \mathrm{COO}^{-}, \mathrm{C}_{2} \mathrm{O}_{4}{ }^{2-}$ and $\mathrm{CH}_{3} \mathrm{SO}_{3}{ }^{3-}$.

The chemical constituents originate from different sources. $\mathrm{Na}^{+}$is of marine origin, $\mathrm{Ca}^{2+}$ is of crust origin and $\mathrm{NO}_{3}{ }^{-}$comes from complex sources. These profiles are shown in Figure 3.
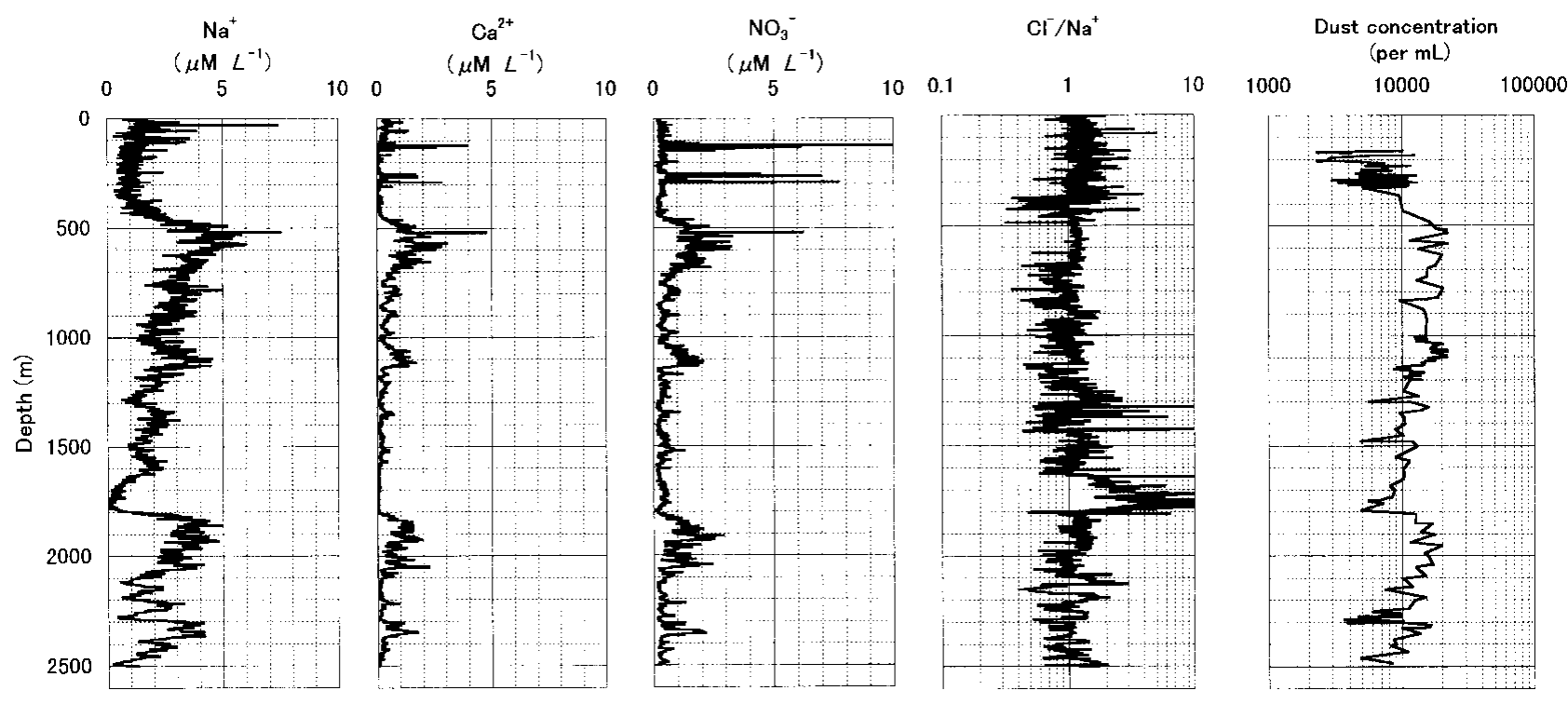

Fig. 3. Profiles of environmental signals in the Dome Fuji deep ice core (preliminary results as of July 1998). 
Comparing these profiles with the oxygen isotopic profile shown in Figure 2, a negative correlation between $\mathrm{Na}^{+}$and $\delta^{18} \mathrm{O}$ through the glacial cycles and a positive correlation between $\mathrm{Ca}^{2+}$ and $\mathrm{NO}_{3}{ }^{-}$during the glacial stages are found. The $\mathrm{Cl}^{-} / \mathrm{Na}^{+}$ratio during the glacial stages was close to the sea-water ratio (1.2 molar ratio). In contrast, lower concentrations of $\mathrm{Cl}^{-}$and $\mathrm{Na}^{+}$and higher ratios of $\mathrm{Cl}^{-}$to $\mathrm{Na}^{+}$are found during interglacial stages.

\section{DUST PARTICLE ANALYSIS}

Dust concentration and size distribution have been analyzed in ice sections $7 \mathrm{~cm}$ long at every $2.5 \mathrm{~m}$ interval along the entire core with a laser particle counting system (Met One Co., 9000 Series Liquid-borne Particle Counting System with Model 211 Light Scattering Sensor). As the core has no significant fractures, we assume that drilling fluid has not contaminated samples.

The total number per $\mathrm{mL}$ of dust particles larger than $0.52 \mu \mathrm{m}$ in diameter is shown in Figure 3. Large dust concentrations occur in the depth ranges 500-820, 1050-1110, 18302200 and $2300-2350 \mathrm{~m}$. The upper three spikes are similar to spikes appearing in the Vostok ice core. These occur during the colder phases of the glacial stages except in the first cold phase after the interglacial stage, probably due either to insufficient wind speed over the source area or to the fact that sea level was still high and the aridity was then not very different from that of the interglacial stage (Petit and others, 1990). On the other hand, the lowest concentrations of dust occur in the Holocene $(\sim 380 \mathrm{~m})$ and the interglacial stages (1740-1820, 2250-2320 and below $2460 \mathrm{~m}$ ).

The ratio of average dust concentrations in sections for the Holocene $(\sim 360 \mathrm{~m})$ to those for the end of the last glacial (430-700 m) is 1/2.5, compared to $1 / 6$ for the Dome C core and 1/3 for the Byrd ice core (Thompson and Mosley-Thompson, 1981).

\section{ICE-CORE GHRONOLOGY}

The time-scale of the Dome Fuji ice core was calculated by using Equation (1) and a steady-state ice-flow model. A simple Dansgaard-Johnsen model was used with ice thickness $H=3028 \mathrm{~m}$ and shear layer thickness $h=1200 \mathrm{~m}$. The iceequivalent thickness of the firn layer is $70.4 \mathrm{~m}$ (the boundary depth of the firn-ice layer is $106 \mathrm{~m}$ ).

The $\delta^{18} \mathrm{O}$ profile with the time-scale obtained is shown in Figure 2. The major features of the Dome Fuji ice core are as follows. (a) The ice core covers the past $340 \mathrm{ka}$ including three glacial-interglacial cycles. (b) All major features of marine isotope stages (MIS) Nos 1-9 are recognized, although the temperature amplitude for long-term variations for Dome Fuji appears to be a few ${ }^{\circ} \mathrm{C}$ higher than that of the Vostok core. (c) The Eemian interglacial is located around 110-130 ka BP, which agrees with the Vostok data within 5\% uncertainty.

Further studies of the core chronology of the Dome Fuji deep ice core are required. Cross-correlation analysis with other core data obtained from comprehensive physical and chemical studies of the Dome Fuji deep ice core will reveal more detailed information on paleoclimate changes in the Southern Hemisphere.

\section{REFERENGES}

Dome-F Deep Coring Group. 1998. Deep ice-core drilling at Dome Fuji and glaciological studies in east Dronning Maud Land, Antarctica. Ann. Glaciol., 27, 333-337.

Dome-F Ice Core Research Group. 1998. Preliminary investigation of palaeoclimate signals recorded in the ice core from Dome Fuji station, east Dronning Maud Land, Antarctica. Ann. Glaciol., 27, 338-342.

Petit, J.-R., L. Mounier, J. Jouzel, Ye. S. Korotkevich, V. M. Kotlyakov and C. Lorius. 1990. Palaeoclimatological and chronological implications of the Vostok core dust record. Nature, 343(6253), 56-58.

Thompson, L. G. and E. Mosley-Thompson. 1981. Microparticle concentration variations linked with climatic change: evidence from polar ice cores. Science, 212 (4496), 812-815.

Watanabe, O. and 13 others. 1997. Preliminary report on analyses of melted Dome Fuji core obtained in 1993. Proc. NIPR Symp. Polar Meteorol. Glaciol. $11,14-23$. 